\title{
Test Study on Uniaxial Compressive Strength of Fine Sandstone after High
}

\section{Temperature}

\author{
Chongbang $\mathrm{XU}^{1, \mathrm{a}^{*}}$ \\ ${ }^{1}$ Research Institute of Highway Ministry Transport, Beijing 100088, China; \\ axubang-2003@163.com
}

\begin{abstract}
Keywords: fine sandstone; high temperature; uniaxial compression strength; mechanical properties. Abstract: The mechanical property and wave velocity of fine sandstone after different high temperature such as $25^{\circ} \mathrm{C} 、 400^{\circ} \mathrm{C} 、 600^{\circ} \mathrm{C} 、 800^{\circ} \mathrm{C}$ and $1000^{\circ} \mathrm{C}$, be test studied by the servo-controlled testing machine RMT-150B and ultrasonic nondestructive testing instrument TUA2000A. The test results show that:(1) the sensitivity of stage from $400^{\circ} \mathrm{C}$ to $800^{\circ} \mathrm{C}$ is remarkable to stage from $25^{\circ} \mathrm{C}$ to $400^{\circ} \mathrm{C}$ and from $800^{\circ} \mathrm{C}$ to $1000^{\circ} \mathrm{C}$ on the wave velocity and quality. (2) the uniaxial compressive strength is increasing in early stage and reducing in later stage according to the temperature, the turning point is $800^{\circ} \mathrm{C}$, and the quadratic polynomial with the conversion between the positive and negative on temperature accurately reflects this change. (3) elastic module is also increasing in early stage and reducing in later stage according to the temperature, and it is the maximum when temperature reaches $400^{\circ} \mathrm{C}$, the minimum when temperature $1000^{\circ} \mathrm{C}$ is only $45 \%$ of initial value.
\end{abstract}

\section{Introduction}

It has great difference for the mechanical properties of rock between before and after high temperature because of its composition, so that the rock change is emphasized in the field about high temperature rock mass, and the change law about wave velocity, elastic modulus and strength of rock after high temperature be analyzed by rock test [1-5]. Haijian $\mathrm{Su}$ [6] claim noted that the peak strength of sandstone is affected by the change of temperature with the increase of temperature, and the failure mode of the specimen is also closely related to temperature and loading rate. Gang $\mathrm{Wu}[7]$ believes that $100^{\circ} \mathrm{C}$ is considered as the threshold value of the crack growth of sandstone, $600^{\circ} \mathrm{C}$ is the threshold value of the internal structure changing of the sandstone, and it presents a clear brittle plastic transition phenomenon beyond $600^{\circ} \mathrm{C}$.Guofei Chen[9] thinks it is great changing of the mechanical properties of marble when its temperature beyond $400^{\circ} \mathrm{C}$, and failure mode from brittle fracture to ductile failure. Shibing Yin[10-11] shows that the strength peak value of sandstone is decreased with its temperature increase, and the greatest decrease occurs in the stage of its temperature over $800^{\circ} \mathrm{C}$.

The wave velocity, elastic modulus and the uniaxial compressive strength of sandstone specimen after high temperature is studied in Shihuoshan tunnel of the Xinjiang Production and Construction Corps. The research results could be as assessment about the tunnel surrounding rock stability after fire and repair reinforcement design reference.

\section{Uniaxial compressive test of rock after high temperature}

Rock specimen preparation

The rock sample come from Shihuoshan tunnel of the Xinjiang Production and Construction Corps, its lithology is sandstone. The sample is processed by the standard cylinder specimen of $100 \mathrm{~mm}$ and length 50mm as Fig.1, its geometry size and apparent quality accord with standard requirement [13]. 


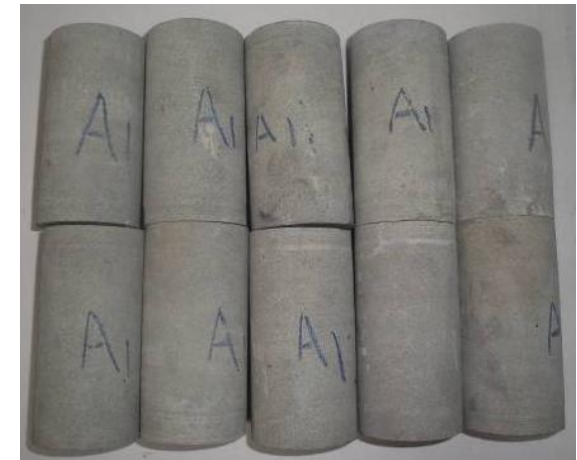

Figure 1. Rockspecimen partly

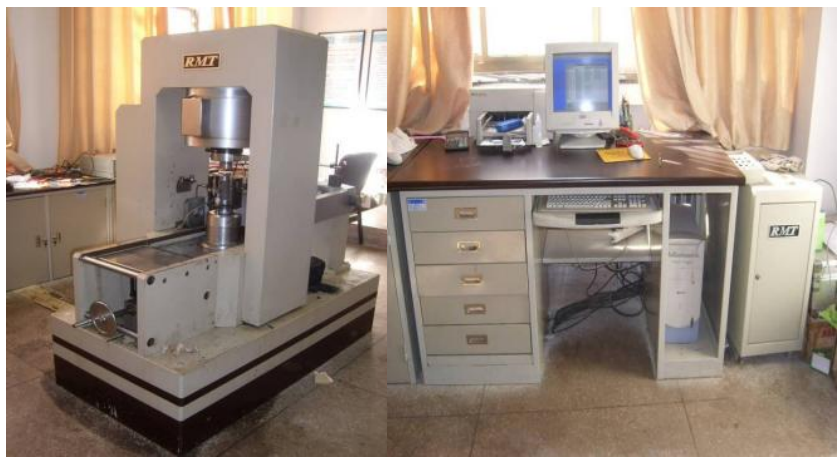

Figure 2. Rock test system RMT-150B

Heating and testing of test specimen

The wave velocity of the specimen was measured by the ultrasonic nondestructive testing instrument TUA2000A, the quality was weighed by the precision electronic balance which accuracy is $0.01 \mathrm{~g}$, and the uniaxial compression test was performed on the servo-controlled testing machine RMT-150B (Fig.2), which was developed by the Wuhan Institute of rock and soil mechanics in Chinese Academy of Sciences. The rock specimen after high temperature test pieces and their uniaxial compressive failure mode are shown in Fig. 3.
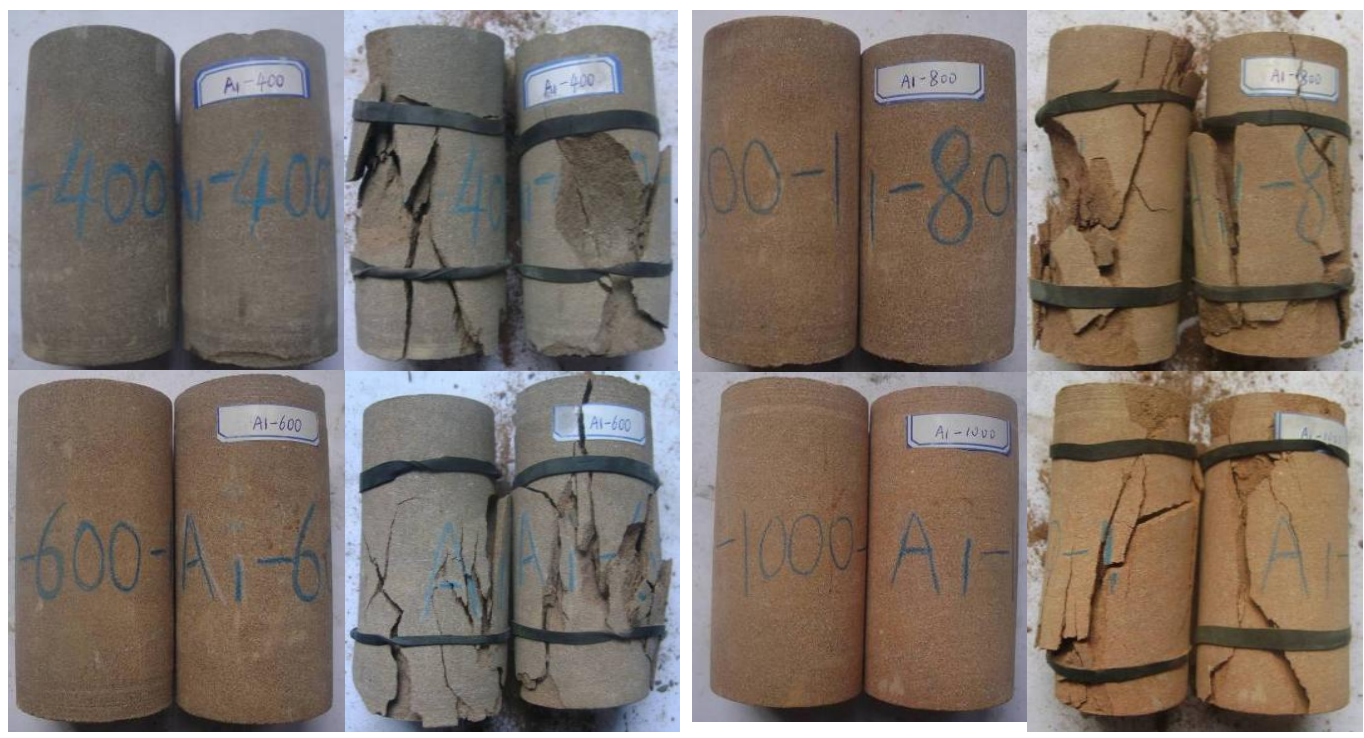

Figure 3. Shapes of rock specimen after experiment

\section{Test results and analysis}

\section{Wave velocity}

Firstly, from the correlation between the data and the temperature, the 5 data sets of wave velocity test show that the rock wave velocity is decreased with the specimen temperature increase, and the decrease is obvious when the temperature is higher (Fig. 4).Compared with the initial wave velocity at general temperature, the wave velocity at $400^{\circ} \mathrm{C}, 600^{\circ} \mathrm{C}, 800^{\circ} \mathrm{C}$ and $1000^{\circ} \mathrm{C}$ decreases by $5 \%, 23 \%, 50 \%$ and $57 \%$ respectively.

Secondly, there is the nonlinear relationship between the wave velocity and temperature, and decreased rate is significantly lower when rock temperature is below $400^{\circ} \mathrm{C}$ or over $800^{\circ} \mathrm{C}$ than the stage of its temperature from $400^{\circ} \mathrm{C}$ to $800^{\circ} \mathrm{C}$.Four sets of the rock wave velocity attenuation value is shown in Fig.5 they that: I the rock wave velocity attenuation is only $129 \mathrm{~m} / \mathrm{s}$ when rock temperature from the general 
temperature to $400^{\circ} \mathrm{C}$. II. it is nearly three times the previous stage, which the rock wave velocity attenuation is $491 \mathrm{~m} / \mathrm{s}$ at the stage of rock temperature $400^{\circ} \mathrm{C}$ to $600^{\circ} \mathrm{C}$. III. the rock wave velocity attenuation is the maximum value in the test, which is $714 \mathrm{~m} / \mathrm{s}$ at the stage of rock temperature $600^{\circ} \mathrm{C}$ to $800^{\circ} \mathrm{C}$. IV $800^{\circ} \mathrm{C}$ to $1000^{\circ} \mathrm{C}$ stage, the rock wave velocity attenuation is $182 \mathrm{~m} / \mathrm{s}$, and the wave velocity decay rate decreases significantly.

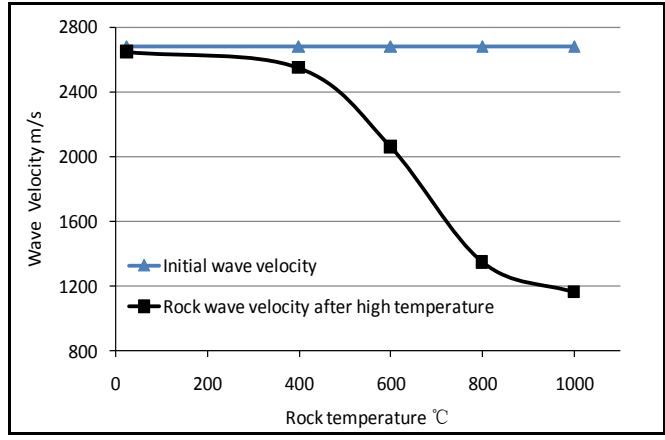

Figure 4. Wave velocity change after high temperature

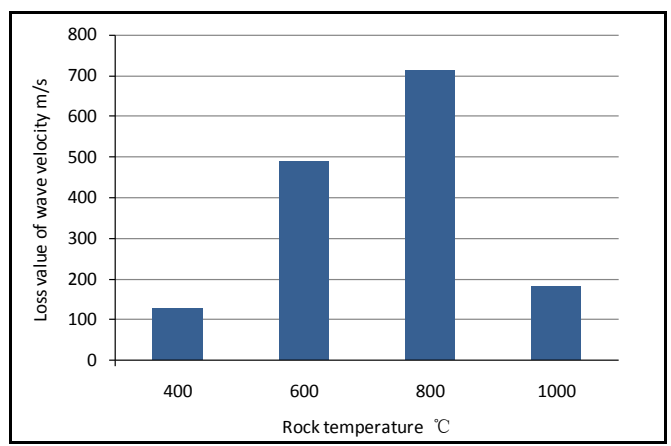

Figure 5. Loss value of wave velocity in different temperature

\section{Density}

Firstly, the rock weight is decreased with the specimen temperature increase, and the lost rate is obvious when the temperature is higher (Fig. 6).Compared with the initial weight at general temperature, the rock weight at $400^{\circ} \mathrm{C}, 600^{\circ} \mathrm{C}, 800^{\circ} \mathrm{C}$ and $1000^{\circ} \mathrm{C}$, decreases by $0.34 \% 、 0.96 \% 、 2.97 \%$ and $3.45 \%$ respectively.

Secondly, it is the nonlinear relationship also between the weight loss rate of rock and temperature, and the loss rate is significantly lower when rock temperature below $400^{\circ} \mathrm{C}$ or over $800^{\circ} \mathrm{C}$ than the stage of its temperature from $400^{\circ} \mathrm{C}$ to $800^{\circ} \mathrm{C}$ (Fig. 7), and the maximum of weight loss at the stage of $600^{\circ} \mathrm{C}$ to $800^{\circ} \mathrm{C}$.

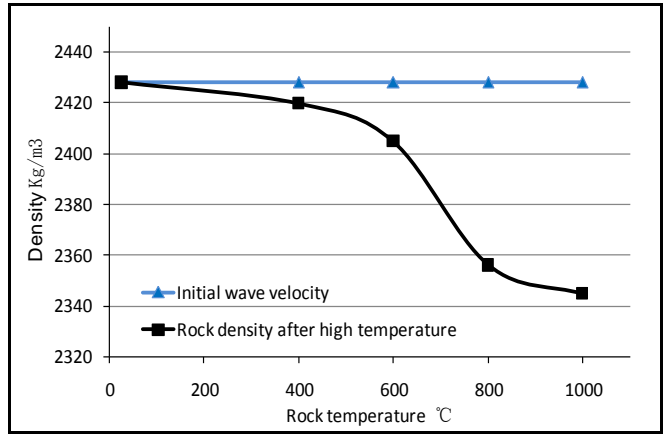

Fig.6 Loss rate of density after high temperature

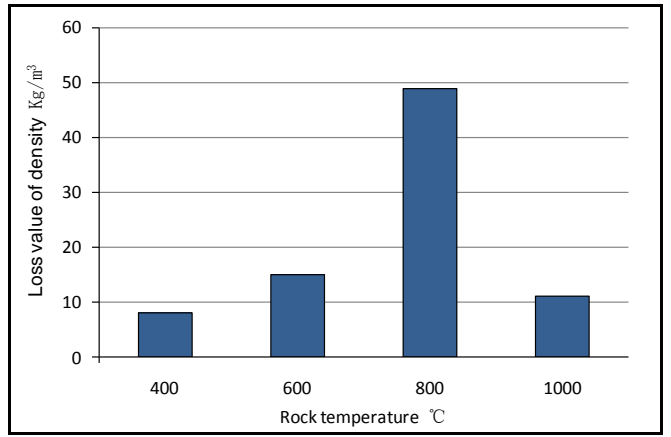

Fig.7 Loss value of density in different temperature

\section{The uniaxial compressive strength}

The relationship between the uniaxial compressive strength and temperature is shown in Fig.8. it shows that the uniaxial compressive strength of fine sandstone increases with temperature increasing at the first stage which rock temperature below $800^{\circ} \mathrm{C}$, and decreases with temperature increasing at the next stage which rock temperature is over $800^{\circ} \mathrm{C}$. And the uniaxial compressive strength of fine sandstone is proportional to the temperature at the stage of rock temperature below $800^{\circ} \mathrm{C}$, and strength change is not obvious at the stage from $600^{\circ} \mathrm{C}$ to $800^{\circ} \mathrm{C}$ which indicates that the favorable influence on maximization and the contact relationship between mineral particles is improved[14]. The uniaxial compressive strength of fine sandstone reaches $83.88 \mathrm{Mpa}$ at temperature $400^{\circ} \mathrm{C}, 95.44 \mathrm{Mpa}$ at temperature $600^{\circ} \mathrm{C}$, and its maximum is $96.16 \mathrm{Mpa}$ when rock temperature reaches $800^{\circ} \mathrm{C}$, which is 1.3 times the general strength $75.3 \mathrm{Mpa}$. The minimum of uniaxial compressive strength is $67.15 \mathrm{Mpa}$ when rock temperature reaches $1000^{\circ} \mathrm{C}$, which is 29.0Mpa lower than maximum, and 8.25 Mpa lower than the general strength.

Therefore, the uniaxial compressive strength is fitted using the two polynomial of temperature, which contains positive and negative conversion, and the relationship is as follows. 

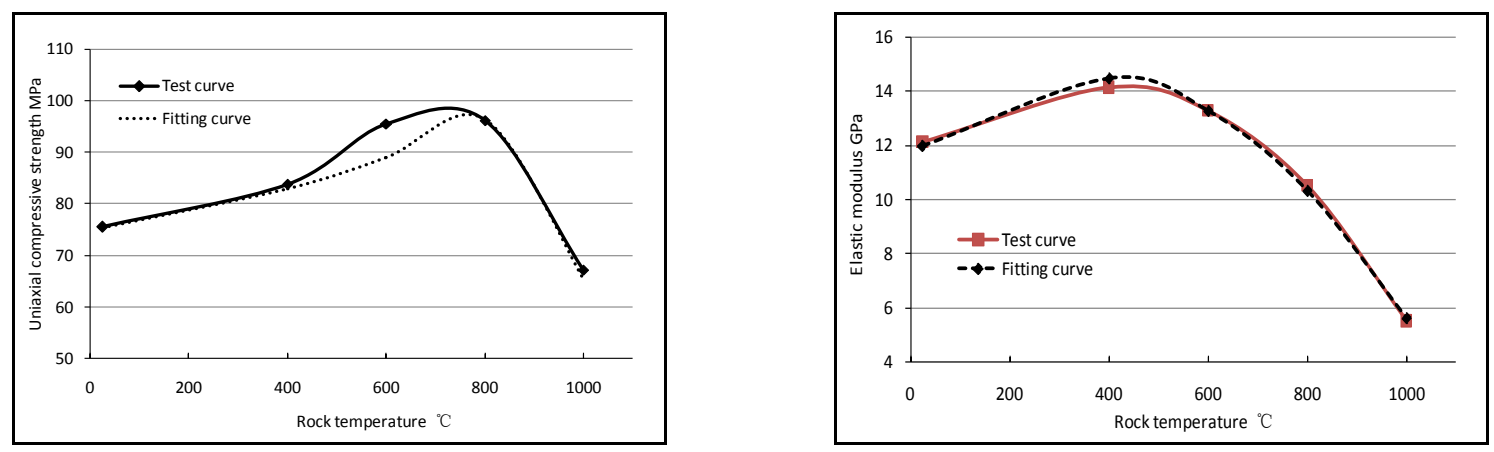

Figure 8. Relation between uniaxial compressive strength and temperature Figure 9. Relation between elastic modulus and temperat ure

$$
\sigma_{c}=\frac{801-t}{|801-t|} \times 2 \times 10^{-5} t^{2}+0.0095 t+76
$$

Where $\sigma_{c}$ uniaxial compressive strength, Mpa; $t$ rock temperature, ${ }^{\circ} \mathrm{C} ; \frac{801-t}{|801-t|}=1$ when $t=801^{\circ} \mathrm{C}$

The relationship between the uniaxial compressive strength calculated value of Eqn. (1) and the test data of rock after high temperature as in Fig. 8, show that the calculated value of Eqn. (1) could reflect the change law of the uniaxial compressive strength of rock after high temperature, agreement with the test data.

\section{Rock deformation parameter}

Elastic modulus. Fig.9 shows that the elastic modulus of fine sandstone increases with temperature increasing at the first stage which rock temperature is below $400^{\circ} \mathrm{C}$, and decreases with temperature increasing at the next stage which rock temperature is over $400^{\circ} \mathrm{C}$, its maximum is $14.15 \mathrm{Gpa}$ when rock temperature is at $400^{\circ} \mathrm{C}$, which is 1.2 times the general elastic modulus, and it is $10.51 \mathrm{Gpa}$ at $800^{\circ} \mathrm{C}$, and the minimum of elastic modulus is $5.5 \mathrm{Gpa}$ when rock temperature reaches $1000^{\circ} \mathrm{C}$, which is only $45 \%$ of the general elastic modulus.

Therefore, the elastic modulus has a strong sensitivity to temperature, and reaches the maximum at $400^{\circ} \mathrm{C}$, it could fit the relationship between the elastic modulus and the temperature of the fine sandstone with the parabola type two polynomial, and the fitting formula is as follows:

$$
E=-2.2 \times 10^{-5} t^{2}+0.016 t+11.62
$$

Where E elastic modulus, GPa;

The dotted line reprints the result of Eqn. (2) in Fig.9, and it shows that the Eqn. (2) could reflect the relationship between the elastic modulus and temperature.

Poisson's ratio. The change is more complex, as shown in Fig10, between the Poisson's ratio of fine sandstone that there is no rule to follow. Therefore the Poisson's ratio could be considered as the constant for slightly variation in test.

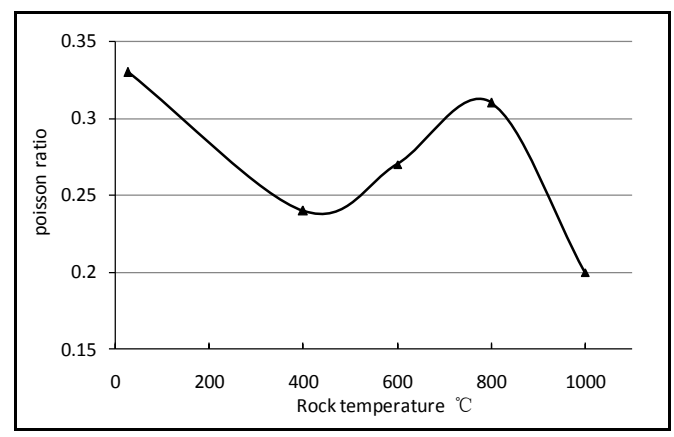

Figure 10. Relation between poisson ratio and temperature 


\section{Summary}

The wave velocity and density to temperature is very similar, which be effected deeply by the temperature of fine sandstone, and it is the very obvious stage from $400^{\circ} \mathrm{C}$ to $800^{\circ} \mathrm{C}$. The uniaxial compressive strength increases with temperature increasing at the stage which rock temperature is below $800^{\circ} \mathrm{C}$, and decreases with temperature increasing at the next stage, and the reduction rate is higher than the growth rate in the previous stage. Eqn. (1) could reflect the change law of the uniaxial compressive strength of rock after high temperature and the Eqn. (2) could reflect the elastic modulus change with temperature.

\section{Acknowledgments}

This study is sponsored by the CNNSF 51008289, the Research Institute of Highway Ministry Transport Foundation, and the Xinjiang Production and Construction Corps Transport Foundation.

\section{References:}

[1] WAN Zhijun, ZHAO Yangsheng, DONG Fuke, et al. Experimental study on mechanical characteristics of granite under high temperature and trixial stresses[J]. Chinese Journal of Rock Mechanics and Engineering, 2008, 27(1): 72-77.

[2] CHEN Lunjian, WU Zhong, QIN Bendong, et al. Mechanical characteristics and cracking mechanism of coal roof sandstone under high temperature[J]. Journal of Chongqing University(Natural Science), 2005, 28(5):123-126.

[3] DU Shouji, LIU Hua, ZHI Hongtao, et al. Testing study on mechanical properties of post-high-temperature granite[J]. Chinese Journal of Rock Mechanics and Engineering, 2004, 23(14): 2359-2364.

[4] DU Shou-ji, MA Ming, CHEN Haohua, et al. Testing study on longitudinal wave characteristics of granite after high temperature[J]. Chinese Journal of Rock Mechanics and Engineering, 2003, 22(11): 1803-1806.

[5] DU Shouji, L IU Hua, CHEN Haohua, et al. Experimental research on the density and wave characteristics of granite rock after high-temperature[J].Journal of Shanghai Jiaotong University, 2003, 37(12):1900-1904.

[6] SU Haijian,JING Hongwen, ZHAO Honghui. Experimental investigation on loading rate effect of sandstone after high temperature under uniaxial compression[J]. Chinese Journal of Geotechnical Engineering, 2014, 36 (6) : 1064-1071.

[7] WU Gang, WANG Deyong, ZHAI Songtao. Acoustic emission characteristics of sandstone after high temperature under uniaxial compression[J]. Rock and Soil Mechanics, 2012,33(11): 3237-3242.

[9] CHEN Guofei, YANG Shengqi . Study on failure mechanical behavior of marble after high temperature [J]. Engineering Mechanics,2014,31 (8) :189-196.

[10] YIN Tubing, LI Xibing, WANG Bin, et al. Study of mechanical properties of sandstones after high temperature under dynamic loading[J]. Chinese Journal of Geotechnical Engineering, 2011, 33(5): 777-784.

[11] YIN Tubing, LI Xibing, YIN Zhiqiang, et al. Study and comparison of mechanical properties of sandstone under static and dynamic loadings after high temperature[J].Chinese Journal of Rock Mechanics and Engineering, 2012,31(2): 273-279.

[13] Coal Industry Ministry of the People's Republic of China. Measuring methods of physico-mechanical property for coal and rock[M]. Beijing: Standards Press of China, 1988: 32-33.

[14] SU Chengdong, GUO Wenbing, LI Xiaoshuang. Experimental research on mechanical properties of coarse sandstone after high temperatures [J]. Chinese Journal of Rock Mechanics and Engineering, 2008, 
27(6): 1162-1170. 